\title{
10
}

\section{Fragile positions in the new paternalism: Indigenous community organisations during the 'Advancement' era in Australia}

\section{Alexander Page}

We are now witnessing one of the largest scale 'upheavals' of Aboriginal and Torres Strait Islander affairs

The introduction and continuation of the Indigenous Advancement Strategy (IAS) by the Abbott and Turnbull Coalition governments has reconstructed the Commonwealth's relationship with the Indigenous sector. ${ }^{1}$ The IAS brought a dramatic upheaval for Aboriginal and Torres

1 The Indigenous sector is the estimated $8-9,000$ community-run or community-based organisations (Bauman et al. 2015) that deliver localised, culturally appropriate services and perform advocacy roles with and for many Aboriginal and Torres Strait Islander peoples across the country (Rowse 2012). They form a unique political entity in the Australian polity, following their dramatic growth in the 1970s as a response to a lack of Indigenous-specific service provision by state and federal governments (Rowse 2012: 104-5; Holcombe \& Sullivan 2013). Aboriginal community organisations are specific projects made by and for Indigenous peoples that speak back to top-down government policymaking through their democratic voluntary association models that practice various forms of grassroots decision-making. Importantly though, the conceptualisation of an Indigenous sector is at best an 'ideal type' (Weber 1949: 90-1). It cannot possibly capture the myriad variety in geographical, socio-historical, economic, political and cultural differences in each organisation, let alone in their relations with the various levels of Australian government and the peoples or populations they serve (Walter \& Andersen 2013: 19). Instead, it is used here to discuss the racialised construction of these organisations by the Australian Government for which policy is then administered. 
Strait Islander community organisations, with many facing potential closure at the introduction of a new competitive funding application with no consultation prior to implementation. Following recent debate regarding Indigenous constitutional recognition, a change in prime minister and the most recent federal election, there seems to be little discussion of the IAS in the broader Australian polity. However, the continuing need to critique the IAS as currently enacted policy is vital (Altman 2014, Cox 2014, Bond 2015, Dodson 2015, Hudson 2016). This analysis seeks to explain the current set of practices used by the Australian Government in its IAS, and the damaging effects of this policy relative to the right of Indigenous peoples' self-governance in early 21 stcentury Australia.

This chapter first critically assesses the introduction and rollout of the IAS (2014 to present). Next, by identifying several glaring issues in contemporary Indigenous affairs policymaking through the process, reactions and results of its introduction, a narrative of topdown, undemocratic, racist and unaccountable programming by the Commonwealth is illustrated. Finally, such an approach to Indigenous affairs is recognised as continuing the neoliberal governance mechanisms and audit technologies used by the Commonwealth in Indigenous affairs policy practice from the mid-2000s, following the dissolution of the Aboriginal and Torres Strait Islander Commission (ATSIC) as a pillar in an 'Indigenous order of Australian government' (Sanders 2002: 8, this volume Chapter 6) and a 'shield' from many major changes in Australian public administration (Sullivan 2011: 70, Strakosch 2015: 33). This chapter argues that during the present 'Advancement' era, the Commonwealth has continued its neo-paternalistic (Altman 2007: 13) practice onto Aboriginal community organisations through neoliberal forms of settler colonial micromanagement and domination (HowardWagner 2015: 88). This attempted control of Indigenous political capacity through the Commonwealth's allegory of deficiency-including an implicit and mandatory requirement for Indigenous 'Advancement'prescribes an 'apolitical' logic of economic rationalism as its 'legitimate' and 'natural' remedy (Pusey 1991: 68). The 'Advancement' sought by the Commonwealth is a reproduction of racialised policymaking with strong parallels to the Protectionism era (Howard-Wagner \& Kelly 2011: 107-10), which then explicitly reproduces the legitimising racial narratives of the Australian state (Goldberg 2002: 10). This chapter records and explains how this neopaternalistic framework has developed since 2013. 
Through an evaluation of the intention of this 'Advancement', the ISA is revealed as a clear example of ongoing domination through 'race in action' (Wolfe 2016: 18) in current Indigenous affairs policy.

\section{The Indigenous Advancement Strategy (2014 to present)}

We will eliminate red tape and streamline programmes to move away from the complex web of overlapping initiatives that have failed to end disadvantage [and legislate] ... real action so that indigenous Australians get the services they need.

$$
\text { —Liberal Party of Australia (2013: 43) }
$$

The fragile position of the Indigenous sector under the current Australian Government's IAS originated prior to its introduction in 2014. The new Abbott Liberal-National Coalition Government, elected on 18 September 2013, committed to audit and significantly cut federal spending in their first budget (Liberal Party of Australia 2013: 4). The National Commission of Audit (NCA) ${ }^{2}$ was engaged to investigate potential government savings that could be accommodated. In their report, Towards responsible government, the NCA (2014: 174) reviewed Indigenous-specific programs, services and spending, concluding there were 'too many disparate and fragmented Commonwealth Indigenous programmes [and a] creeping overlap of responsibilities between the Commonwealth and State [governments]'. The NCA (2014: 177) recommended 'consolidation' and 'rationalisation' of Indigenous services from 150 to 'no more than six or seven programs'. In aiming to improve the oversight and strategic coordination of Indigenous Affairs, the NCA pushed for the establishment of a new agency that would report directly to the Australian Department of the Prime Minister and Cabinet (PMC). While mirroring the calls of many recent government reports, ${ }^{3}$ the NCA provided no analysis or supporting evidence of its own in its calculations. Furthermore, the repeated use of the word 'likely' in the report regarding savings and service improvement for Indigenous populations that would potentially result from these changes revealed a lack of confidence in

\footnotetext{
2 The NCA was headed by then chairman of the Business Council of Australia, Tony Shepard.

3 See Australian National Audit Office (2012: 19-24), Department of Finance (2011: 12), Productivity Commission (2010: xxvi, 116).
} 
their success (NCA 2014: 172-7). Regardless, the Abbott Government enthusiastically took up the recommendations of the NCA in its first budget wholesale.

Budget 2014-15 (May 2014) introduced a restructuring of the relationship between the Indigenous sector and the Australian Government under the newly announced IAS. Major changes included a AU\$534.4 million cut in service delivery funding 'through efficiencies resulting from the rationalisation of Indigenous programmes'. The 150 programs and services previously run by a range of departments were centralised into PMC and the Department of Health. These programs and their new funding applications would now fall into five overarching categories: 'Jobs, Land and the Economy; Children and Schooling; Safety and Wellbeing; Culture and Capability; and Remote Australia Strategies' to 'eliminate waste and duplication' (Australian Government 2014: 185, PMC 2014a: 11-17, 2015: 6-8). In just six months, the Abbott Government had centralised the state-sector funding relationship in a near-complete reversal of the 'whole-of-government' and mainstreaming approach to Indigenousspecific funding and programs introduced by the Howard Coalition Government in 2004-05 (Sullivan 2011: 49). Following the dismantling of ATSIC as a 'central Indigenous affairs agency' since its establishment in 1990, Indigenous-specific programs had been placed into multiple federal government departments in an effort to 'mainstream' services (Sullivan 2011: 50). However, this new centralisation (Janet Hunt, pers. comm, November 2016) under the IAS put Indigenous affairs policy directly at the apex of the Australian Public Service: from eight departments, directly into PMC (Hudson 2016: 8).

With no prior consultation, Aboriginal community organisations across the country had only six weeks to reapply for their funding through a brand-new application system, with little instruction, or face potential closure (Gooda 2014: 28, Oscar 2014, FPARC 2016: 40). This 'new flexible programme structure' (PMC 2014b: 9) aimed to construct a single funding agreement for organisations with the department to reduce extensive bureaucratic overlap and auditing requirements that have burdened the sector for decades (Hudson 2016: 9). The most significant change was the PMC's adoption of 'open competitive grants rounds' (FPARC 2016: 6) for existing service providers. Over the next several months though, many Indigenous communities would actively campaign to maintain their services under this new bureaucratic regime, due to its tumultuous rollout and the Commonwealth's lack of engagement with the pre-existing Indigenous sector. 


\section{The fragile position of community organisations: Process, reactions, results}

You can't just say 'oh well, scrap that'. What do we do, take the money back? The IAS is a great step forward ... we have picked the best providers

-Nigel Scullion MP, Minister for Indigenous Affairs

(cited in Morgan 2015)

The ad hoc implementation of the IAS was significantly destabilising for many Indigenous community organisations. The Commonwealth's attempt to 'rationalise' and 'reduce red tape' (Scullion 2014, PMC 2015: 8) faced protest and public disapproval from communities, organisations, and peak bodies during its rollout. The IAS created much confusion and funding chaos in this process by adding new layers of bureaucratic oversight, and centralised control in the Minister for Indigenous Affairs, Nigel Scullion (FPARC 2016: 14). Over time, this control directly increased the possibility of closures for many Indigenous organisations, prompting negative evaluations from organisations who lacked instructions on how to comply with the application to continue funding services deemed vital by communities (Gooda 2014: 20-8, Anderson 2015). One day prior to submitting the application, June Oscar (2014) detailed the process as having 'a distinct absence of Aboriginal inclusion, participation, and local self-determination in devising these outcomes', the IAS being a 'classic case of government policy incoherence that Indigenous people have been dealing with for decades'.

By early 2015, the first IAS funding allocation announcement saw many within the Indigenous sector express disappointment, with government departments, 'universities, churches, and ... sporting organisations' receiving the majority of funding (Henderson 2015) rather than local Indigenous organisations who had been delivering their own successful culturally specific programs for many years (Davis 2015, The Redfern Statement 2016: 5). ${ }^{4}$ Multiple protests outside the minister's office (Everingham 2015) eventually pushed the Commonwealth into reversing

4 A total of AU\$860 million of funding was allocated to '964 organisations delivering 1,297 projects in 2015' (Scullion 2015). A list of the organisations who received funding approval in 2014 under the IAS, including the program component and value of that agreement is available (see PMC 2014c). A list of individual grants approved in financial years 2014-15 and 2015-16 is also available (see PMC 2016a). 
some of the proposed cuts to funding, such as to Aboriginal legal services (Murphy-Oates 2016). At present though, the majority of funding is yet to be restored (Russell 2016: 4).

Public anger regarding funding cuts and application process confusion resulted in an inquiry by the Senate Finance and Public Administration References Committee (FPARC 2016). The inquiry highlighted substantial problems and consequences of the IAS, finding that no consultation was undertaken with organisations regarding the changes, resulting in the many 'non-compliant' IAS applications. All contracts were extended for six months as a result (FPARC 2016: 9, 14-15, 36-40, Scullion 2014). The 'quick transition' also created significant 'uncertainty in the sector', with many smaller organisations closing due to staffing difficulty and lacking the considerable resources required to fill in the extensive application form (FPARC 2016: 45). Even as applications were filled, the five aforementioned funding streams were unable to account for complex social issues and programs for some organisations (FPARC 2016: 18-19). If organisations received over AU $\$ 500,000$ in funding, they were also now required to incorporate under the Corporations (Aboriginal and Torres Strait Islander) Act 2006 (Cwth), thus increasing their reporting requirements unless demonstrating they were 'well-governed' and 'highperforming' (Bond 2015, PMC 2015: 19). Finally, the competitive tender model also disadvantaged already administratively overburdened local organisations, now competing with each other for contractual funding from a reduced funding pool (FPARC 2016: 21-3).

In creating this new 'rationalised' process the now central PMC improvised to ensure the delivery of vital services of many organisations. Personal phone calls to and from the minister and organisations were required in some cases to make sure service gaps were filled in this process (PMC 2014a: 9, FPARC 2016: 5-11). Even within PMC, the framework created issues for Indigenous public servants, with Biddle and Lahn (2016: 8) noting that many fell into the 'deeply uncomfortable position as the "messenger of bad news" to Indigenous organisations and communities' on behalf of the Australian Government's IAS.

During the federal election campaign of July 2016, Indigenous Affairs Minister Scullion said nothing about the IAS, maintaining what Langton (2016) called a 'very loud silence' about their 'disastrous new model of funding for the Indigenous Sector'. While the department held public consultation forums in October 2015 (Scullion 2015), resulting in the 
competitive nature of grants being downplayed, there has been little else done to ameliorate this situation. This is despite dozens of national Indigenous peak bodies calling on the government to reform the IAS through a restoration of funding and a 'greater emphasis on ... local Aboriginal and Torres Strait Islander organisations as preferred providers' (Davidson 2016, The Redfern Statement 2016: 5). As government ignores voices of the Indigenous sector resisting, negotiating and rejecting this policy, an examination of the underpinning values of the IAS and its restructuring of the state-sector relationship is vital to highlight the ongoing racialised framework of this 'Advancement' era.

\section{The neopaternalism of the 'Advancement' era}

While we are expected to meet every compliance requirement, how do we ensure equal accountability on the part of this government?

$$
\text { - June Oscar (cited in Davis 2015) }
$$

After the abolition of ATSIC in 2004-05, the Commonwealth continues to 'Advance' a particular style of governance and policy regime onto Aboriginal and Torres Strait Islander populations, whereby neoliberalism and settler colonial paternalism are combined (Howard-Wagner \& Kelly 2011, Strakosch 2015: 33-50). The practice of neoliberal settler colonial policymaking, as evidenced by the introduction of the IAS, has two major components I wish to highlight here. First is the vigorous integration of new public management mechanisms into government interaction with Indigenous organisations (Sullivan 2011: 70). This includes a highly strict auditing culture, specific governance rules monitored by overseer and legislation, and control of the direction of programs and services that can be offered through centralised decision-making (Rowse 2012: 121, Holcombe \& Sullivan 2013: 499, Adams 2014: 274). Second, ongoing settler colonial policy formation, and the framing of those mechanisms through this lens, means policy is racialised in particular ways for Aboriginal and Torres Strait Islander peoples and Indigenous community organisations (Howard-Wagner \& Kelly 2011: 119-20). They are tailored specifically for the Indigenous sector through a deficit narrative, whereby Indigenous peoples are supposedly lacking agency and political capacity (despite the very nature and continued existence of the Indigenous sector), thus requiring significant governmental intervention (Bielefeld 2016: 158, Wolfe 2016). As the existence of the Indigenous 
sector undermines Commonwealth legitimacy by challenging its attempt to control all policymaking and delivery from the ground up (Page 2015), the IAS continues to erode the political capacity of grassroots community organisations who seek to improve Indigenous wellbeing through democratic, self-determining means.

Such a policy framework manifests itself as neopaternalism, which here denotes policy regimes that are imposed without consultation, [as] topdown, racist, non-discretionary, [and] disempowering' (Altman 2007: 13) for Indigenous peoples who are deemed in need of 'intense supervision because they are less inclined to adhere to mainstream behavioural norms' (Bielefeld 2016: 156). The language of paternalism then is a link to previous caustic policy regimes of control, domination and oppression by Australian governments over the last two centuries (Altman 2007, Howard-Wagner \& Kelly 2011, Bond 2015). Aboriginal and Torres Strait Islander peoples were excluded, dispersed and then 'protected' by state governments, being forced into missions where they had little control over their own lives and no civil rights, and were denied cultural and social maintenance (Broome 2010: 149-226, Howard-Wagner \& Kelly 2011: 107-9). An 'authoritarian paternalism' has been gaining precedence since the abolishment of ATSIC, manifesting explicitly following the Northern Territory Emergency Response of 2007, whereby Indigenous 'dissent [is] repositioned as dysfunction' and an incapacity to comply with a nonnegotiable rationalised contract results in further legitimised 'paternalistic intervention' (Strakosch 2015: 162-3). The legislative arithmetic of the largely bipartisan nature of Australian politics, where both major parties largely agree on Indigenous affairs policy, also means there is little accountability for policymakers when implementing these new policy regimes onto Indigenous lives (Davis 2015, 2016). Neopaternalism then is able to use and reproduce these racist frameworks in early 21 st-century policy, as 'regimes of race' are constructed as ongoing and 'ever-incomplete projects' (Wolfe 2016: 18).

Racialised new public management mechanisms that flow from this neopaternalism take specific shape for the Indigenous sector (Adams 2014: 272-89, Howard-Wagner 2015: 93, Sullivan this volume, Chapter 11). Even as the Indigenous sector fills the gaps of state services and provides alternatives in culturally relevant ways, the Commonwealth's neoliberal settler colonialism disregards this contribution of Indigenous peoples and is unable to understand grassroots, place-specific, 'culturally informed local third-sector organisations' (Sullivan this volume, Chapter 11). 
The IAS amplified total financial control, an extensive auditing culture, rigorous bureaucratic oversight and a newly required incorporation into Indigenous-specific legislation, moving back towards economic and political 'guardianship' as seen under the assimilationist and protectionist eras (Sanders 2014: 168). Antithetically, the Commonwealth's IAS makes decisions for Indigenous peoples on the 'logic' of a seemingly invisible racialised and 'neutralised' economic rationalism (Pusey 1991: 68), with the minister ultimately facing no accountability to the communities it affects. The Commonwealth has 'picked the best providers' (Scullion, quoted in Morgan 2015) in a way that is anarchic, chaotic and at the minister's personal discretion, while expecting a total assimilation of organisations into strict, non-negotiable regulatory frameworks, all on the government's terms (Anderson 2015: 58, Lea 2008, 2012: 116, Sullivan 2011). When combined with the non-consultative, total 'upheaval' (Gooda 2014: 14) of implementation, this severely damages the ability of Indigenous peoples to govern their own lives via culturally specific organisations (Davis 2015), under the guise of 'benevolent intentions' towards economic development (Bielefeld 2016: 157).

The Australian racial state continues this approach through dual narratives of racial hierarchy, both of which frame indigeneity as deficiency: naturalism, or 'the claim of inherent racial inferiority' of Indigenous peoples, and historicism, whereby Indigenous peoples are in need of 'progression' for their wellbeing (Goldberg 2002: 74). Policy is then made via this framing to maintain the state's own distinct nationalism, which legitimised the paternalistic 'Advancement' of Indigenous people. Through this allegory of deficiency, Indigenous peoples are assumed to have no political capacity, or civil society, in order to maintain the narrative of Australian nationalism and white hegemony and control over policy settings and service delivery mechanisms (McCallum 2011: 609, Strakosch 2015: 67-9). This allows the Commonwealth to continue practising racist strict regulation, governance and economic management of Indigenous peoples' lives under the IAS as 'Advancement' through a veil of economically rational legitimacy (Goldberg 2009: 355-56), while simultaneously facing very little accountability for the damage of this relationship (Sullivan 2009: 62, Howard-Wagner 2015) and in the denial of public servants' own agency in the process (Lea 2008: 18-19). The 'Advancement' era then 'rationalises' this ongoing racialisation process of the Australian state as normal. 
The IAS reveals how these actively racialised mechanisms are utilised by 21st-century Australian governments as neoliberal practice positioned as natural, logical and rationalised. Indigenous populations of Australia face the dual impact of this process: the settler state's continuing reproduction of, and exclusion by, white hegemony (Goldberg 2002: 104), and in utilising neoliberal policymaking, becoming 'more robust in its controlling than enabling or caretaking conditions, more intrusive, more repressive [in an] intensification of [the capitalist state's] core features' (Goldberg 2009: 333). Such programs then reproduce a 'long-established socio-economic hierarchy with racialised consequences' (Bielefeld this volume, Chapter 8). For example, funding reliance means it is difficult for Indigenous sector organisations to survive while providing culturally specific services (Adams 2014: 271). The Indigenous sector then continues to negotiate, resist and comply within a policy framework, which demands organisations never-endingly seek an impossible 'earned autonomy' (PMC 2016b: 22) as evidence of their own 'Advancement' in whatever means a largely unaccountable, racist and dominating Australian Government decides.

\section{'Advancement' for whom, to where?}

Make no mistake, Indigenous Affairs is in deep crisis

—Noel Pearson (2016)

With little change to the IAS at the time of writing, and the recent announcement of AU\$52.9 million in IAS funding in Budget 2017-18 to create an 'Enhanced Research and Evaluation in Indigenous Affairs' program to evaluate its processes (Haughton 2017), the 'Advancement' era's mechanisms of neoliberal settler colonialism and the dismantling of the rights of Indigenous peoples to self-govern continues. The IAS does little to foster the unique facets of Indigenous civil society, instead damaging Indigenous capacity via new bureaucratic demands that an already overburdened sector must now negotiate. It reproduces a continuing power inequity between government and the Indigenous sector, pushing away opportunities for a trusting and productive relationship of government and the Australian Public Service with Aboriginal and Torres Strait Islander peoples and organisations. Instead, the Commonwealth practices neopaternalism for populations it views as incapable of making their own decisions about what governance and service delivery arrangements work best for them (Sullivan 2011). 
This paternalism undertaken in the name of 'Advancement' then is purely 'race in action' (Wolfe 2016: 10), reproducing a continuing narrative in Indigenous affairs policy of 'the "good" white [knowing] what is best for the deficient, "dysfunctional" Indigenous "other"' (Howard-Wagner \& Kelly 2011: 120) behind a thin veil of 'neutralised' economic rationalism (Pusey 1991: 68). The IAS reveals the Australian Government's power to act unilaterally in attempting to constrain Indigenous political capacity, while Aboriginal and Torres Strait Islander peoples must continue to negotiate this attempted control through community organisations in the pursuit of social justice, in an increasingly precarious position. The allegory of deficiency gives government a 'legitimated' impetus to continue this neopaternalism, resting upon the de-legitimation and continued attempts to exclude and remove Indigenous sovereignty, authority and legitimacy over the past 200 years. The persistence of the Indigenous sector's survival and negotiation contradicts this framing. Despite the sector's success in providing relevant services to Indigenous peoples for over four decades, the Australian Government seems only to be 'listening, but they are not hearing' (Davis 2016: 82). While organisations across the country will continue to actively negotiate with the Commonwealth as a funding provider, the Indigenous sector will become more precarious if there is no change to the responsibilities that govern this relationship. Australian Government mechanisms such as the IAS entrench racial power disparity and do nothing to 'Advance' Aboriginal and Torres Strait Islander peoples' right to self-governance.

\section{References}

Adams E (2014). Losing ground? Issues of autonomy in an urban Indigenous organisation. PhD thesis, The Australian National University, Canberra.

Altman JC (2007). The Howard government's Northern Territory Intervention: Are neo-paternalism and Indigenous development compatible? Topical Issue Paper 16/2007, Centre for Aboriginal Economic Policy Research, The Australian National University, Canberra.

Altman JC (2014). Abbott's back to the future policy for Aboriginal advancement. New Matilda, 17 June, newmatilda.com/2014/06/17/abbotts-back-futurepolicy-aboriginal-advancement/.

Anderson I (2015). The crisis of Australia's Indigenous policy. Meanjin 74(3):54-9. 
Australian Government (2014). Budget 2014-15: Budget measures budget paper no. 2 2014-15, Commonwealth of Australia, Canberra.

Australian National Audit Office (2012). Australian government coordination arrangements for Indigenous programs, Commonwealth of Australia, Canberra.

Bauman T, Smith D, Quiggin R, Keller C \& Drieburg L (2015). Building Aboriginal and Torres Strait Islander governance: Report of a survey and forum to map current and future research and resource needs, Australian Institute of Aboriginal and Torres Strait Islander Studies, Canberra.

Biddle N \& Lahn J (2016). Understanding Aboriginal and Torres Strait Islander employee decisions to exit the Australian public service, Working Paper 110, Centre for Aboriginal Economic Policy Research, The Australian National University, Canberra.

Bielefeld S (2016). Neoliberalism and the return of the guardian state: Micromanaging Indigenous peoples in a new chapter of colonial governance. In Sanders W (ed.), Engaging Indigenous economy: Debating diverse approaches, ANU Press, Canberra, doi.org/10.22459/CAEPR35.04.2016.12.

Bond C (2015). Nothing new in Indigenous reform agenda. Croakey Blog, 16 March, blogs.crikey.com.au/croakey/2015/03/16/unfair-and-arbitrary-isthe-only-thing-new-in-the-indigenous-advancement-strategy-a-new-roundof-a-massive-funding-cuts/.

Broome R (2010). Aboriginal Australians: A history since 1788, 4th edn, Allen \& Unwin, Sydney.

Cox E (2014). What works - and why the budget measures don't. Journal of Indigenous Policy, 16:1-112.

Davidson H (2016). 'We vote too': Indigenous groups warn both parties they want action. Guardian, 9 June, www.theguardian.com/australia-news/2016/ jun/09/we-vote-too-indigenous-groups-warn-both-parties-they-want-action.

Davis M (2015). Gesture politics: Recognition alone won't fix Indigenous affairs. The Monthly, December-January, www.themonthly.com.au/issue/2015/ december/1448888400/megan-davis/gesture-politics.

Davis M (2016). Listening but not hearing: When process trumps substance. Griffith Review 51:73-87.

Department of Finance (2011). Strategic review of Indigenous expenditure: Report to the Australian Government, www.finance.gov.au/foi/disclosure-log/2011/ foi_10-27_strategic_reviews.html. 
Dodson P (2015). Tony Abbott's lifestyle comments highlight the lack of policy in Aboriginal affairs. Age, 13 March, www.theage.com.au/comment/ tony-abbotts-lifestyle-comments-highlight-the-lack-of-policy-in-aboriginalaffairs-20150311-141u4s.

Everingham S (2015). Indigenous Affairs Minister faces angry protest in Alice Springs. PM, 30 March, www.abc.net.au/pm/content/2015/s4207607.htm.

FPARC (Finance and Public Administration References Committee) (2016). Commonwealth Indigenous Advancement Strategy tendering processes, Commonwealth of Australia, Canberra.

Goldberg DT (2002). The racial state, Blackwell, Massachusetts.

Goldberg DT (2009). The threat of race: Reflections on racial neoliberalism, Blackwell, Massachusetts.

Gooda M (2014). Aboriginal and Torres Strait Islander Justice Commissioner: Social justice and native title report 2014, Australian Human Rights Commission, Sydney.

Haughton J (2017). Budget review 2017-18: Indigenous affairs-government priority areas, Commonwealth of Australia, Canberra.

Henderson A (2015). Majority of grants from Indigenous Advancement Strategy first round given to non-Aboriginal groups. $A B C N e w s, 5$ May, www.abc.net. au/news/2015-05-05/majority-of-indigenous-grants-go-to-non-aboriginalorganisations/6444534.

Holcombe SE \& Sullivan P (2013). Australian Indigenous organisations. In Douglas Caulkins M \& Jordan AT (eds), A companion to organisational anthropology, Blackwell, Massachusetts.

Howard-Wagner D (2015). Child wellbeing and protection as a regulatory system in the neoliberal age: Forms of Aboriginal agency and resistance engaged to confront the challenges for Aboriginal people and community-based Aboriginal organisations. Australian Indigenous Law Review 19(1):88-102.

Howard-Wagner D \& Kelly B (2011). Containing Aboriginal mobility in the Northern Territory: From 'protectionism' to 'interventionism'. Law, Text, Culture 15(7):102-34.

Hudson S (2016). Mapping the Indigenous program and funding maze. Research Report 18, The Centre for Independent Studies.

Langton M (2016). Silent issues: The silence on Indigenous issues in the 2016 election. Saturday Paper, 11 June. 
Lea T (2008). Bureaucrats and bleeding hearts: Indigenous health in northern Australia, UNSW Press, Sydney.

Lea T (2012). When looking for anarchy, look to the state: Fantasies of regulation in forcing disorder within the Australian Indigenous estate. Critique of Anthropology 32:109-24, doi.org/10.1177/0308275X12438251.

Liberal Party of Australia (2013). Our plan: Real solutions for all AustraliansThe direction, values and policy priorities of the next Coalition Government. Liberal Party of Australia, Canberra.

McCallum D (2011). Liberal forms of governing Australian Indigenous peoples. Journal of Law and Society 38(4):604-30, doi.org/10.1111/j.14676478.2011.00560.x.

Morgan M. (2015). Turnbull Government to retain similar policies to Abbott: Scullion. NITV News, 22 September, www.sbs.com.au/nitv/article/2015/ 09/21/turnbull-government-retain-similar-policies-abbott-scullion.

Murphy-Oates L (2016). NSW Indigenous legal line still facing funding uncertainty, says CEO. NITV News, 9 March, www.sbs.com.au/nitv/thepoint-with-stan-grant/article/2016/03/09/nsw-indigenous-legal-line-stillfacing-funding-uncertainty-says-ceo.

NCA (National Commission of Audit) (2014). Towards responsible government: Phase one. Commonwealth of Australia, Canberra.

Oscar J (2014). Turning community action into national policy, University of Sydney Charles Perkins Annual Oration, 30 October, Sydney.

Page A (2015). The Australian settler state, Indigenous agency, and the Indigenous sector in the twenty first century. Proceedings of the Australian political science association conference, University of Canberra, September, Canberra.

Pearson N (2016). Address to the National Press Club, 27 January, Canberra.

PMC (Australian Government Department of the Prime Minister \& Cabinet) (2014a). Indigenous Advancement Strategy guidelines 2014, www.dpmc.gov. $\mathrm{au} /$ resource-centre/indigenous-affairs/indigenous-advancement-strategyguidelines-july-2014.

PMC (2014b). The indigenous advancement strategy, www.dpmc.gov.au/ indigenous-affairs/indigenous-advancement-strategy.

PMC (2014c). Indigenous advancement strategy grant round reporting 2014, www. pmc.gov.au/indigenous-affairs/grants-and-funding/ias-2014-grant-roundreporting. 
PMC (2015). Submission to the Senate Finance and Public Administration References Committee: Impact on service quality, efficiency and sustainability of recent Commonwealth Indigenous Advancement Strategy tendering processes by the Department of Prime Minister and Cabinet, www.aph.gov. au/Parliamentary_Business/Committees/Senate/Finance_and_Public_ Administration/Commonwealth_Indigenous.

PMC (2016a). IAS grant reporting (Excluding IAS 2014 grant round), www.dpmc. gov.au/indigenous-affairs/grants-and-funding/ias-grant-reporting.

PMC (2016b). Indigenous Advancement Strategy grant guidelines March 2016Amended May 2016, www.dpmc.gov.au/resource-centre/indigenous-affairs/ indigenous-advancement-strategy-grant-guidelines-march-2016.

Productivity Commission (2010). Contribution of the not-for-profit sector, Commonwealth of Australia, Canberra.

Pusey M (1991). Economic rationalism in Canberra: A nation-building state changes its mind, Cambridge University Press, Cambridge.

The Redfern Statement (2016). res.cloudinary.com/www-changetherecord-orgau/image/upload/v1465428796/The_Redfern_Statement_-_9_June_2016_ FINAL_h7mvy9.pdf.

Rowse T (2012). Rethinking social justice: From 'peoples' to 'populations', Aboriginal Studies Press, Canberra.

Russell L (2016). 2016-17 Budget: Indigenous affairs. Menzies Centre for Health Policy, Sydney.

Sanders W (2002). Towards an Indigenous order of Australian government: Rethinking self-determination as Indigenous affairs policy, Discussion Paper 230, Centre for Aboriginal Economic Policy Research, The Australian National University, Canberra.

Sanders W (2014). Experimental governance in Australian Indigenous affairs: From Coombs to Pearson via Rowse and the competing principles. Discussion Paper 291, Centre for Aboriginal Economic Policy Research, The Australian National University, Canberra.

Scullion N (2014). A new era of Indigenous grant funding commences, media release, indigenous.gov.au, www.indigenous.gov.au/new-era-indigenous-grantfunding-commences. 
Scullion N (2015). \$860 million investment through Indigenous Advancement Strategy grants round, media release, www.indigenous.gov.au/news-andmedia/announcements/minister-scullion-860-million-investment-throughindigenous-advancement.

Strakosch E (2015). Neoliberal indigenous policy: Settler colonialism and the 'post-welfare'state, Springer, New York, doi.org/10.1057/9781137405418.

Sullivan P (2009). Reciprocal accountability: Assessing the accountability environment in Australian Aboriginal affairs policy. International Journal of Public Sector Management, 22(1):57-71, doi.org/10.1108/ 09513550910922405.

Sullivan P (2011). Belonging together: Dealing with the politics of disenchantment in Australian Indigenous policy, Aboriginal Studies Press, Canberra.

Walter M \& Andersen C (2013). Indigenous statistics: A quantitative research methodology. Left Coast Press, California.

Weber M (1949). The methodology of the social sciences, The Free Press, Glencoe, Illinois.

Wolfe P (2016). Traces of history: Elementary structures of race. Verso, London, doi.org/10.1111/1468-229X.12265. 
This text is taken from The Neoliberal State, Recognition and Indigenous Rights: New paternalism to new imaginings, edited by Deirdre Howard-Wagner, Maria Bargh and Isabel AltamiranoJiménez, published 2018 by ANU Press, The Australian National University, Canberra, Australia.

doi.org/10.22459/CAEPR40.07.2018.10 